\title{
Development of a Computer Controlled Automated PCB Machine
}

\author{
Metin Salihmuhsin, Sabit Baba, Ahmet Serdar Y1lmaz, Mustafa Sekkeli \\ Kahramanmaraş Sütçü İmam Üniversitesi, Mühendislik ve Mimarlık Fakültesi, Elektrik Elektronik \\ Mühendisliği, Kahramanmaraş, 46100, Türkiye
}

\begin{abstract}
A PCB machine that can draw trace lines and drill holes on a PCB card is developed. The machine consists of a computer, a driving circuit and a mechanical setup. The overall system is operated and controlled from a computer through a program written in Matlab. A relay based driving circuit is developed to perform operations onto the mechanical setup. A communication protocol is established between the computer and the driving circuit through LPT1 port. In this initial work, we demonstrate that the machine successfully draws a trace line and drill holes on two pads which are at both ends of the line. Currently the machine is used only for educational purposes at Microprocessor Control and Instrumentation lab of Kahramanmaras Sutcu Imam University and is utilized at development of educational boards for our labs.
\end{abstract}

Keywords: PCB machine; PIC 18F452 Microcontroller; Step motors

\section{Bilgisayar Kontrollü Otomatik Otomatik PCB Makinesinin Gelişimi}

\author{
Metin Salihmuhsin, Sabit Baba, Mustafa Şekkeli, Ahmet Serdar Y1lmaz
}

Kahramanmaraş Sütçü İmam University, Faculty of Engineering and Architecture, Department of Electrical and Electronic Engineering, Kahramanmaraş, 46100, Turkey

\section{Özet}

Bu çalışmada PCB karları üzerine yolları oluşturabilen ve pad'lerin orta noktalarına delik delebilen bir cihaz geliştirilmiştir. Cihaz bir bilgisayar, bir sürücü devresi ve bir mekanik aksamdan oluşmaktadır. Sistemin tümü Matlab'te yazılan bir program tarafından kontrol edilmektedir. Mekanik aksam üzerinde yaptırılacak hareketlerin kontrolü röleler kullanılarak geliştirilen bir elektronik devre ile yapılmaktadır. Bilgisayar ile sürücü devresi arasındaki haberleşme protokolü bilgisayarın LPT1 portundan gerçekleştirilmiştir. Bu ilk çalışmamızda cihazımızın başarılı bir şekilde bir PCB kartı üzerine bir adet yol çizdiğini ve yolun her iki tarafında bulunan padlerin orta noktalarına birer delik deldiğini göstermekteyiz. Şu anda cihazımız sadece eğitim amaçlı olarak laboratuvarımızda kullanılmaktadır.

Anahtar Kelimeler: PCB Cihazı; PIC 18F452 Mikrodenetleyici; Step motorlar

\section{Introduction}

Systems that can assembly electronic cards from their circuit drawings are used in so many places from industry to university labs. Typically, production of a PCB card requires trace lines to be drawn, holes to be drilled and soldering to be done on a circuit board. Nowadays, these processes are done by expensive equipment. The price of these equipment ranges on the order of tens of thousands of dollars. There are many places where there is need for a cheaper device that could automate either all of or some parts of the above mentioned processes. We will brief two related studies below.

Hodges and Richard had developed a cheaply constructed robot mechanism and added a computer vision system to it to obtain a PCB drilling mechanism. With some minor modifications, their mechanism could be used for placement of surface mount components on a PCB as well. They reported that their system drill holes on a PCB with 
an accuracy of mean error of $0.07 \mathrm{~mm}$. The mean error was calculated by measuring Euclidian distance between the center of each pad and the center of each hole drilled on the application board. Their system also successfully achieved the job of placement of surface mount components onto the PCB. Their aim in that study was to construct a cheap robot and then write sophisticated software for the vision system of the robot such that the robot could achieve jobs that were only achievable by highly expensive robots. The total cost of their system was around 1000 pound. They indicated that their system ran with comparable speed with a commercially available PCB assembly machine with a price of 10000 pound. They also indicated that their system accurately placed surface mount components on a PCB. Further details of their study can be obtained from $[3,4,6]$.

Onwubolu et. al. [5] developed a PC-based computer numerical control (CNC) drilling machine. Both the machine and the driving circuitry were built in house. They have used a PC as a separate front-end interface for the drilling machine. The system they had developed integrated several features such as customized machine control unit, enhanced parallel port communication and neural network based optimizer in order to find the best distance optimized sequence of points to be drilled. They have reported successful drilling of PCBs with their system.

In our previous work, we have demonstrated brief overview of a PCB machine that was developed at our Control and Instrumentation Lab of Kahramanmaras Sutcu Imam University [1]. There, we had shown that the PCB machine were able to draw an "L" shape trace line on a PCB card and drill two holes on the midpoint of two pads which are at both end of the trace line. In another study of ours [2], we have given development of a transistor based driving circuit for the PCB machine developed at our lab and showed that it successfully increased the operation speed of the PCB machine and enhanced it's range of operation.

\section{Goals of This Study}

This study demonstrates complete implementation details of the PCB machine developed at our lab both in hardware and software aspects. The system consists of a mechanical setup of that can move in $\mathrm{X}, \mathrm{Y}$ and $\mathrm{Z}$ directions, a computer, a driving circuit and a software program. The driving circuit is developed to control the mechanical setup as well as to communicate with the computer. The software program is developed to control overall operation of the machine.

\section{Method}

The PCB card drawing and drilling system is developed by using mechanical setup of an old $\mathrm{CNC}$ machine. The mechanical setup has a flat layer on which PCB is put on it to be processed. Above the flat layer, there is a drill that can move along $\mathrm{X}$ and $\mathrm{Y}$ axis. The drill can also move up and down for a specified amount of distance. There is a bit connected to the bottom of the drill. Both trace lines and holes are produced using this bit. An actual picture of the system is shown in the Fig 1.

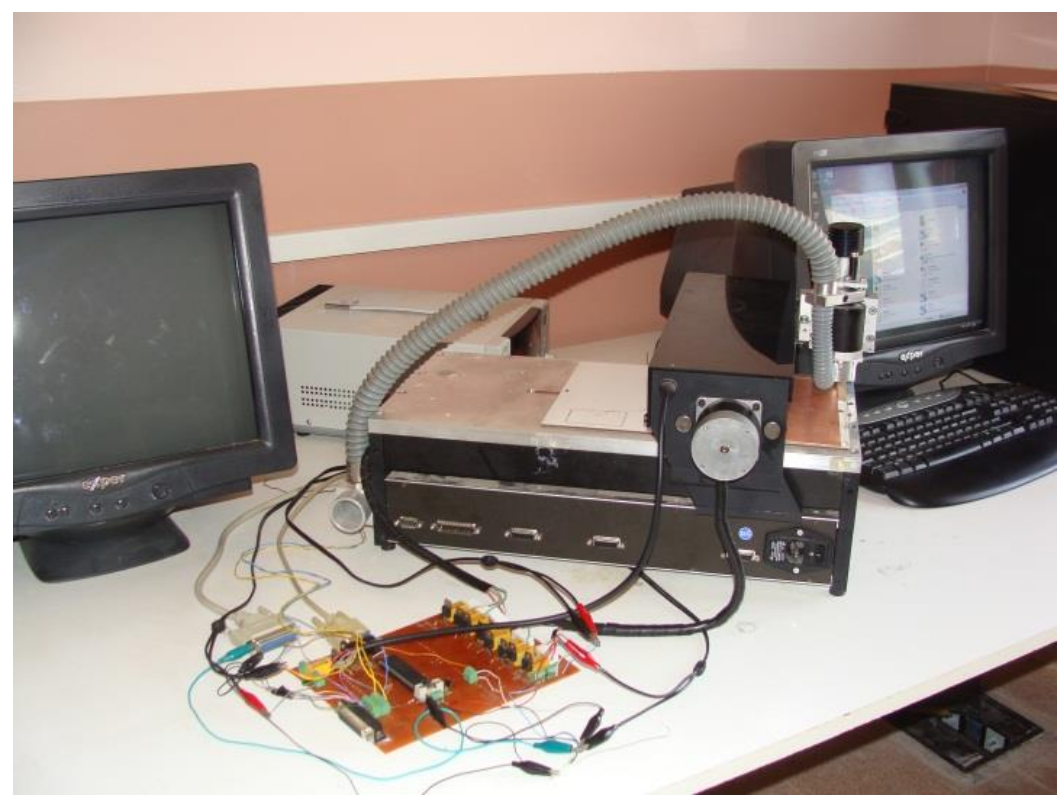

Figure 1. An actual picture of the mechanical setup. 


\section{Hardware Description}

We have designed and developed a driving circuit given in the Figure 2 in order to operate the PCB machine. The driving circuitry is developed using a PIC 18F452 micro controller, transistors and relays. It controls and runs specific functions of the machine such as running step motors to move the machine in $\mathrm{XY}$ axis, running the drill and enabling/disabling an actuator that moves the drill up or down. It also communicates with computer via LPT1 port. The computer is used to perform specific tasks such as sending coordinates of trace lines and pads to the driving circuitry and receiving acknowledge signals from the PIC. A program is written in Matlab to achieve overall control of the machine and to perform data communication between computer and driving circuitry. Coordinates of trace lines and pads are kept in an Excel file in the computer. We now explain the above tasks in detail.

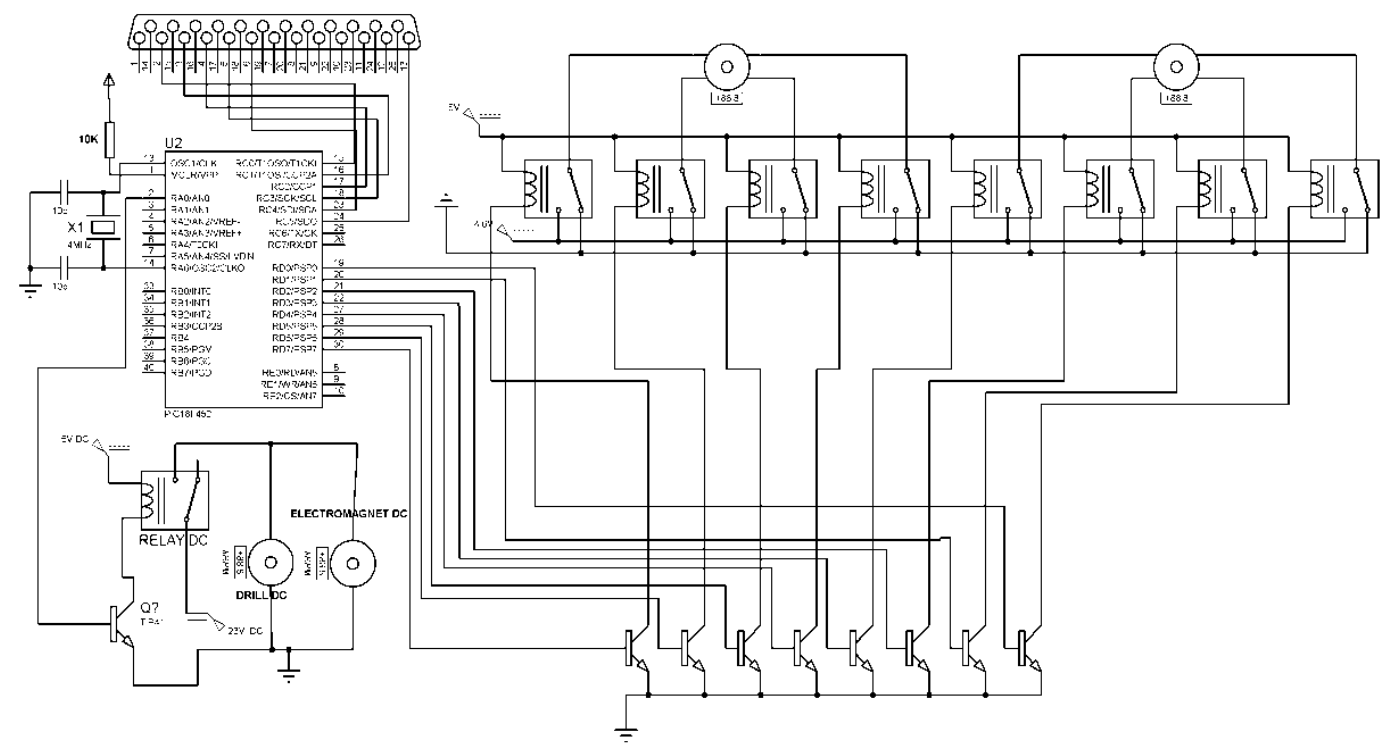

Figure 2. The schematic of the driving circuitry.

There are two bipolar step motors on the mechanical pieces of the PCB machine. One is responsible for the movement in $\mathrm{X}$ direction and the other performs a similar movement in Y direction. Control of both step motors are performed via PIC 18 F452's PORTD pins. $P O R T D<3-0>$ pins are used to control and run the first step motor. PORTD $<7-4>$ pins are used performing similar duties for the second step motor. The portion of the $\mathrm{PCB}$ that moves in $\mathrm{X}$ and $\mathrm{Y}$ directions has a drill placed on it which performs all trace drawings and hole drillings actions. The drill is turned on / off using PIC's PORTC $<4>$ pin. There is a drill actuator placed on top of the drill. When triggered, it moves the drill down to a specified amount of distance and keeps it there steady. The drill actuator is controlled by the same pin that runs the drill, i.e. PORTC $<4>$ pin. There are four sensors placed on both end of the driving way in $\mathrm{X}$ direction and $\mathrm{Y}$ direction of the machine. When one of these sensors is activated, it means the drill reached to it's boundary in that direction. Sensor interfacing is used to detect these boundary reached signals. Communication between PIC and computer is done via LPT1 port. Six lines of LPT1 are utilized: 2, 3,
4, 5, 6 and 13. Lines 2 and 4 are used to move drill in $\mathrm{X}$ direction towards forward and reverse. These lines are connected to PORTC $<0>$ and PORTC $<2>$ pins of the PIC respectively. Lines 3 and 5 are used in a similar way to move drill in $\mathrm{Y}$ direction. These lines communicate with the PIC through PORTC $<1>$ and PORTC $<3>$ pins. Line 6 is used by computer to change the position of the drill to either up or down. It is connected to PORTC $<4>$ pin of the PIC. Finally line 13 of LPT1 port is used by computer to receive data from the driving circuitry. It is attached to PORTC $<5>$ pin of the PIC.

As mentioned earlier, the PCB machine achieves the movement of the drill along XY directions with 2 bipolar step motors. This type of motors has 2 windings without a center-tap. PIC runs both step motors in single phase full step mode. One full turn of a motor is achieved by sending signals given in the below figure to motor windings through related 4 pins of PORTD. The graphical illustration of a bipolar step motor windings are given in the Figure 3(a) and steps needed to run the step motor are given in the Figure 3(b). 


\begin{tabular}{|c|rcccc|}
\hline $120-0000-01 \mathrm{~b}$ & & $1 \mathrm{a}$ & $2 \mathrm{a}$ & $1 \mathrm{~b}$ & $2 \mathrm{~b}$ \\
$2 \mathrm{a} 0-0000-02 \mathrm{~b}$ & STEP 1 & 1 & 0 & 0 & 0 \\
& STEP 2 & 0 & 1 & 0 & 0 \\
STEP 3 & 0 & 0 & 1 & 0 \\
(a) & STEP 4 & 0 & 0 & 0 & 1 \\
\hline
\end{tabular}

Figure 3. (a) A bipolar step motor windings. (b) 4 steps needed to run the step motor in one phase full step mode.

\section{Software Description}

The coordinates of edge of the trace lines and center point of pads are kept in a Microsoft Excel file. To generate this Excel file, the layout of the circuit that needs to be drawn onto the PCB is generated using Proteus schematic drawing and simulation software. ARES program of the Proteus software is used to draw the layout. For this initial study, we only draw an ' $L$ ' shape trace line and two pads onto a PCB card. After the layout file is drawn, an image file for the layout is generated in color and at $300 \mathrm{dpi}$. Then, we have developed an image processing algorithm in Matlab which processes this image file and extracts coordinates of edges of the trace lines and center point of pads. A detailed description of this program will be given in our future studies. The image processing program stores these coordinates into an Excel file according to the format given in the Table 1 .

Table 1. The text file format of coordinates of edges of trace lines and center point of pads

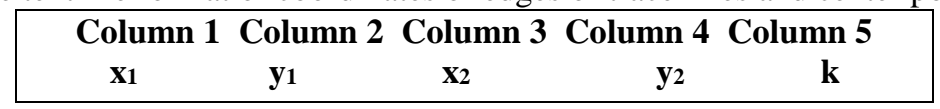

In the Table $1,\left(\mathrm{x}_{1}, \mathrm{y}_{1}\right)$ pair indicates a center point coordinate of a pad to be drilled, $\left(\mathrm{x}_{2}, \mathrm{y}_{2}\right)$ denotes coordinate of an edge point of a trace line. $\mathbf{k}$ is a constant value which takes values of either 0 or 1 . When $\mathbf{k}=0$, it indicates the drill is at up position.
When $\mathbf{k}=1$, it indicates the drill is at down position. The image of the layout used in this study and the Excel file generated by the image processing algorithm for this file are given in the Figure 4(a) and (b) respectively.

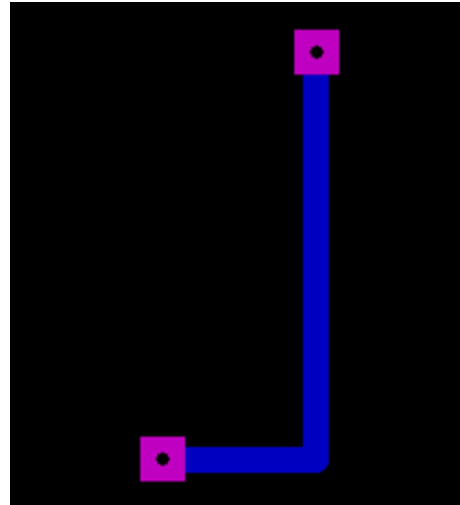

(a)

\begin{tabular}{|c|c|c|c|c|c|}
\hline & \multicolumn{2}{|c|}{ A1 } & \multicolumn{2}{|l|}{+0} & 6,212521452 \\
\hline 4 & A & B & C & D & $E$ \\
\hline 1 & 6,212521 & 7,228521 & 5,164667 & 6,180667 & 0 \\
\hline 2 & 26,19385 & 14,76385 & 5,249333 & 6,180667 & 1 \\
\hline 3 & 0 & 0 & 5,334 & 6,180667 & 1 \\
\hline 4 & 0 & 0 & 5,418667 & 6,180667 & 1 \\
\hline 5 & 0 & 0 & 5,503333 & 6,180667 & 1 \\
\hline 6 & 0 & 0 & 5,588 & 6,180667 & 1 \\
\hline 7 & 0 & 0 & 5.672667 & 6.180667 & 1 \\
\hline 8 & 0 & 0 & 5,757333 & 6,180667 & 1 \\
\hline 9 & 0 & 0 & 5,842 & 6,180667 & 1 \\
\hline 10 & 0 & 0 & 7,281333 & 6,180667 & 1 \\
\hline 11 & 0 & 0 & 7,281333 & 6,604 & 1 \\
\hline 12 & 0 & 0 & 7,366 & 6,688667 & 1 \\
\hline 13 & 0 & 0 & 26,416 & 6,688667 & 1 \\
\hline 14 & 0 & 0 & 26,50067 & 6,773333 & 1 \\
\hline 15 & 0 & 0 & 26,58533 & 6,773333 & 1 \\
\hline
\end{tabular}

(b)

Figure 4. (a) The image of the Layout used in this study. (b) The Excel file generated by the image processing program.

There are 2 separate programs running in parallel in order to operate the PCB machine. The first program runs in the PIC $18 \mathrm{~F} 452$. It is written in assembly language and performs actual step motor driving, runs the drill, accomplishes electromagnet on/off operations and sends acknowledge signals to the computer. The second program runs in the computer and controls overall operation of the whole process. It is written in Matlab. It reads coordinates from an Excel file, sends them to the driving circuit to be processed and receives data from driving circuitry. It also determines on/off status of the drill, enable/disable status of the electromagnet and sends appropriate signals to the PIC to implement these statuses. The Figure 5 shows the block diagram for the duties that are performed by both the assembly and the Matlab program and their interactions with each other. 

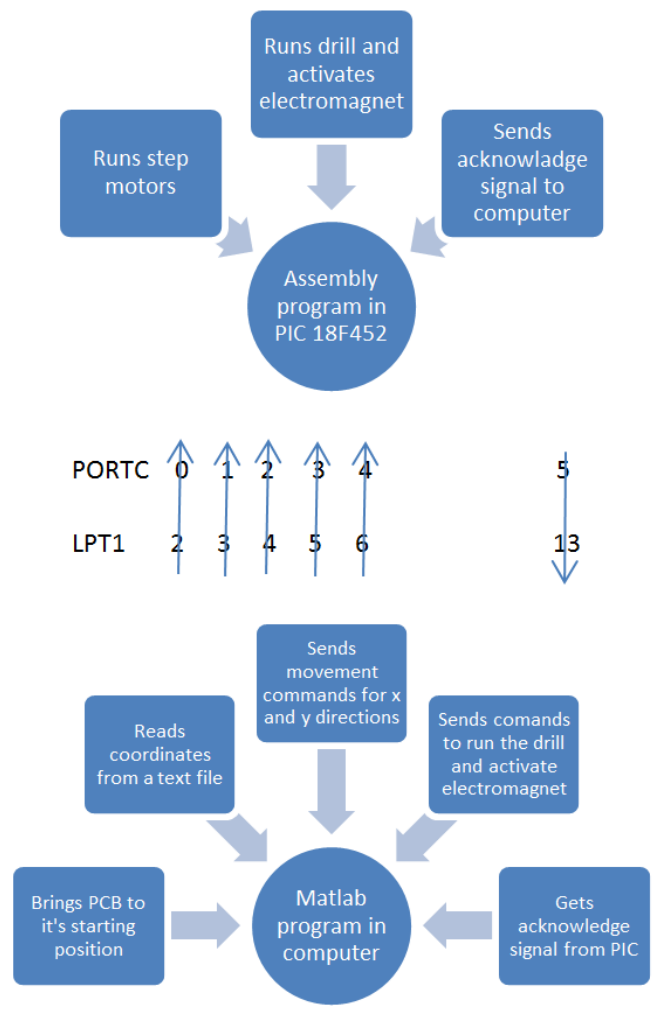

Figure 5. Block diagram of the programs of PCB machine and their interactions with each other.

The Matlab program processes the coordinates of trace lines first and then processes the coordinates of holes to be drilled. Before trace lines are drawn on the PCB card, the user of the PCB machine needs to adjust the position of the drill head to a pre-specified place which gives the drill bit an ability to reach about $0.5 \mathrm{~mm}$ below the surface of the PCB card. When processing of all trace line coordinates are completed, the user needs to adjust the position of the drill head to a pre-specified relatively low position to drill holes. After this adjustment, the drill bit could reach as far as $2 \mathrm{~mm}$ below the surface of the PCB card.

Overall operation of the PCB machine related with the assembly and the Matlab programs is described as follows. When the PCB machine is turned on, the Matlab program sends commands to the driving circuit through LPT1 port to bring the PCB machine's drill head to a pre-defined starting position. The XY coordinate of this initial position is assumed to be $(0,0)$. While this action is in progress, the drill head is at up position and the electromagnet that is connected to the drill head is at off position. Then, the Matlab program reads the first coordinate of the trace line from previously generated Excel file. The $\mathbf{k}$ value for the first coordinate is always zero. This indicates that while the drill is moving towards this coordinate, the head is at up position. Upon receiving on top of the first coordinate, the Matlab program reads the second coordinate from the Excel file. The $\mathbf{k}$ value for this coordinate has to be 1 . The Matlab program sends a command to run the drill and activate the electromagnet to bring the drill head at down position through LPT $1<6>$ line. Then, it sends movement commands for $\mathrm{x}$ and $\mathrm{y}$ directions through LPT1<2,3> lines to the driving circuit. When the PIC $18 \mathrm{~F} 452$ receives these movement commands through it's PORTC $<0,1>$ pins, it runs each of the related bipolar step motors for 4 steps (one complete cycle). The operation causes the drill head to perform a constant value of displacement in $\mathrm{x}$ direction. The same thing is valid for a displacement in y direction. This constant value of displacement is determined in advance and stored in the Matlab file. When the Matlab program receives an acknowledge signal from the PIC, it adds this constant displacement value to both $\mathrm{x}$ and $y$ value of the first coordinate of the trace line and compares results with the $\mathrm{x}$ and $\mathrm{y}$ values of the second coordinate. If results of additions are not equal or greater than the values in the second coordinate, the Matlab program sends movement commands through related LPT1 lines again. The process is repeated until the $\mathrm{x}$ and $\mathrm{y}$ values of the second coordinate are reached. It is the repetition of this process that generates trace lines onto the PCB card. The above duties are performed continually 
by the PIC and the Matlab program until all edge coordinates of the trace lines are drawn.

Processing movement commands for both $\mathrm{x}$ and $\mathrm{y}$ values at each step give the PCB machine ability to draw sinusoidal type shapes onto the PCB card. However, since we only process two trace lines that are perpendicular with each other in this initial study, both $\mathrm{x}$ and $\mathrm{y}$ coordinates seem to be not changing together from one point to another in the Figure 4(b) except at line 14. Both actions, i.e. running the drill and activating electromagnet, are performed through PORTA $<0>$ pin. This is because both duties require the same dc voltage to be applied which is $23 \mathrm{~V}$. Since only $5 \mathrm{~V}$ can be obtained from PORTA $<0>$ pin, an amplification circuit consisted of a transistor and a relay is used to perform application of $23 \mathrm{~V}$ to the drill and the electromagnet.

If PCB machine reaches it's one of the boundaries in either $\mathrm{x}$ or $\mathrm{y}$ directions while drawing a trace line, the related sensor activates. The activation of the sensor cuts the communication between PIC and the computer through LPT1<13> line. Consequently, the Matlab program cannot receive the acknowledge signal which is sent by the PIC after 4 steps of the step motor. Hence the Matlab program stops sending further movement signals to the driving circuit at that direction. Once processing of all trace line coordinates are completed, the Matlab program sends commands to the PIC to bring the drill head to it's starting position again. At this moment, the user needs to adjust the position of the drill head to a pre-specified lower position to drill the holes.

To start processing center coordinates of pads, the Matlab program reads the coordinate of the first hole from the Excel file and sends required command to the PIC to bring the drill head on top of that coordinate. During this action, the drill head is kept at up position and the electromagnet at off position. The Matlab program then sends a command to both run the drill and activate the electromagnet. As oppose to trace drawing, the drill head does not move during the hole drilling process. The drilling process takes about one second. The drill head has a certain mechanism such that when the electromagnet is activated, the drill head goes down and also the head is being pressed onto the PCB card with some amount of pressure. This ensures that the head always stays onto the PCB card with some amount of pressure at this position. It also shortens the time for drilling. Once drilling of the first hole is completed, the Matlab program reads the coordinate of the second hole and repeats the same process until coordinates of all holes are processed. The processing of the PCB card completes, upon hole drilling of all pads are finished.

\section{Experimental Results and Discussions}

The block diagram of the driving circuitry was given in the Figure 2. There, it can be seen that the driving circuitry of a step motor is constructed with 4 relays. Hence for each step in the Figure 3(b), only one relay needs to be triggered. Since each relay's triggering circuit is constructed with a coil winding, there is limitation on how fast we can switch the relay to on and off positions. This limitation also determines how fast we can run the PCB machine. To find the fastest operating speed of the step motor, we experimented with 3 different delay values that are applied in between 4 steps. These values are: 14 milisecond (msec), $56 \mathrm{msec}$ and $3.5 \mathrm{msec}$. During each experiment we have measured 2 voltage values. The first measurement was the voltage obtained from PORTD pin of the PIC which triggers the relay. The second measurement was the $4.6 \mathrm{~V}$ that was applied to terminals of the motor winding when the related relay was triggered. We have displayed both measurements on the oscilloscope screen together. The Figure 6(a), (b) and (c) show these measurements for 3 different delay values.

In the Figure 6(a), the first signal is the voltage on PORTD $<0>$ pin and is shown in blue. It is actually supposed to be $5 \mathrm{~V}$. However, since it is connected to base of a TIP 41C transistor in order to trigger the relay, it appears as $1.25 \mathrm{~V}$. The relay responds to this triggering signal approximately $4 \mathrm{msec}$ later and applies $4.6 \mathrm{~V}$ to the winding of the step motor which is shown in red in the figure. This causes the step motor to perform one turn of its shaft. After 14 msec delay, step completes and the PIC's PORTD $<0>$ pin returns to $0 \mathrm{~V}$. Approximately 1 $\mathrm{msec}$ later, the relay disconnects $4.6 \mathrm{~V}$ from terminals of the motor winding. The Figure 6(b) shows a similar plot for the case where $56 \mathrm{msec}$ delay is applied in between each step.

In Figure 6(c), we have applied $3.5 \mathrm{msec}$ delay in between each step. The figure shows that, although there is $1.25 \mathrm{~V}$ at the PIC's PORTD $<0>$ pin, $4.6 \mathrm{~V}$ is not applied to the motor winding. As we have mentioned above, this is a limitation that comes from construction of the relay. By the time the triggering of the relay is completed which is about 4 msec, the step completes as well and the PIC disables the relay when the relay is about to connect $4.6 \mathrm{~V}$ to the terminals of the motor winding. Hence the motor shaft does not turn at all. 


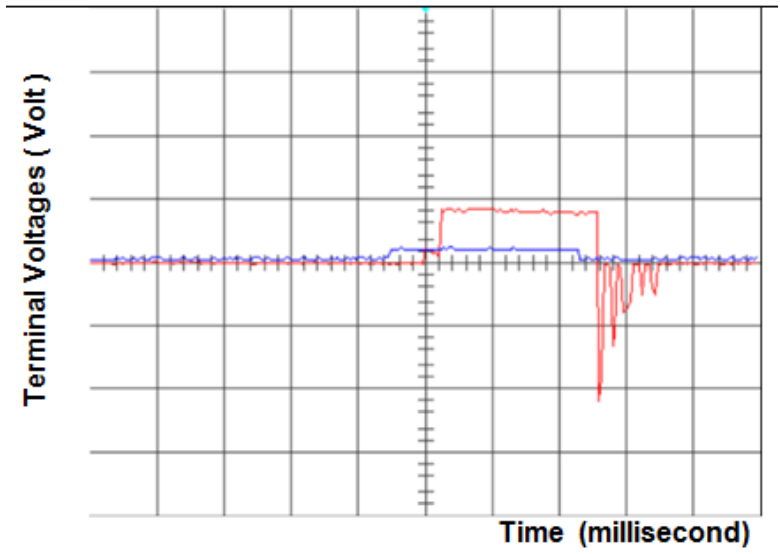

(a) Channels Volt/Div $=5 \mathrm{~V}$; Time $/$ Div $=5$ millisecond

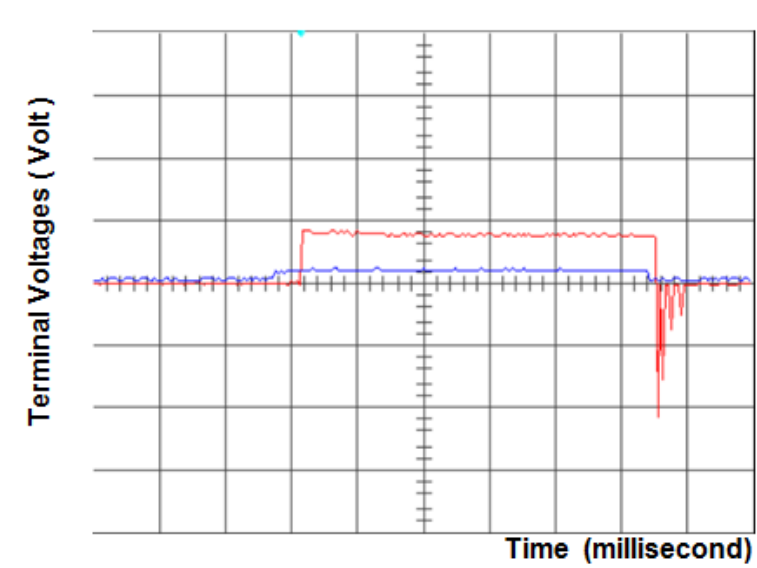

(b) Channels Volt/Div $=5 \mathrm{~V}$; Time $/$ Div $=10$ millisecond

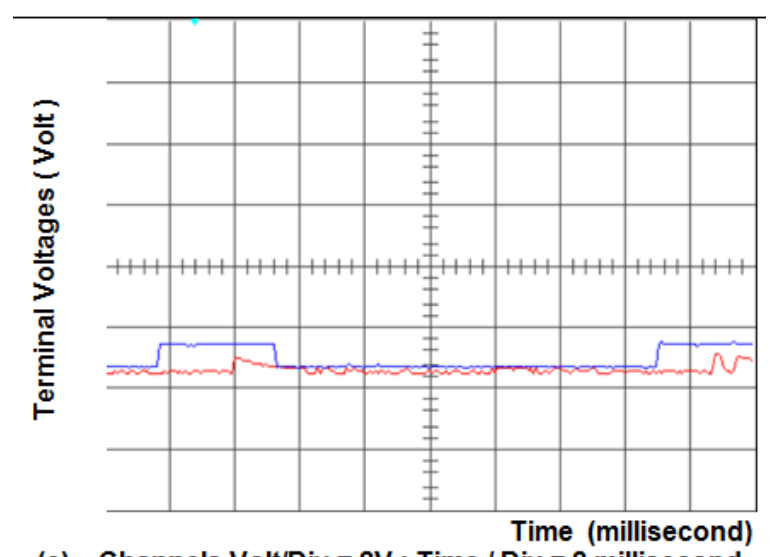

(c) Channels Volt/Div $=2 \mathrm{~V}$; Time $/$ Div $=2$ millisecond

Figure 6. PIC PORTD $<0>$ pin output voltage and $4.6 \mathrm{~V}$ voltage applied to the terminals of the step motor for 3 different delay values: (a) $14 \mathrm{msec}$ (b) $56 \mathrm{msec}$ (c) $3.5 \mathrm{msec}$

\section{Results}

The PCB machine that we have developed performed drawing of a trace line and drilled holes on both end of the trace line successfully. The Figure 7 shows a picture of the processed PCB card.

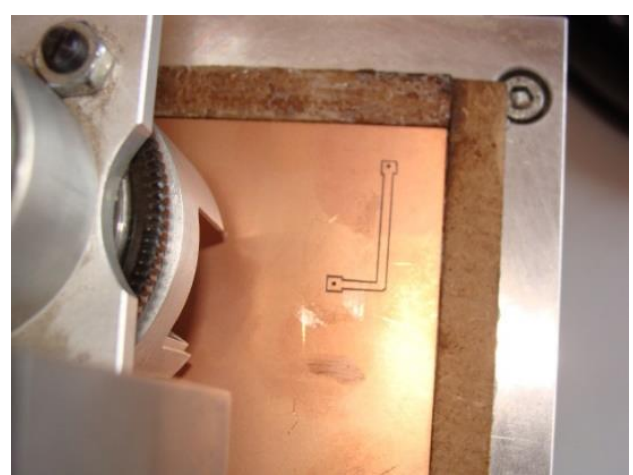

Figure 7. Picture of a PCB card after processed by the PCB machine.

\section{Conclusion}

We have designed and developed a PCB machine that is able to draw trace lines and drill holes on a single layer PCB board. We have tested our system and showed that the PCB machine successfully drew a trace line and drilled holes on both end of the line. The system is developed for educational purpose and is currently in use at Microprocessor Control and Instrumentation Lab at Kahramanmaras Sutcu Imam University.

In our future works, we will continue to enhance different aspect of the PCB machine in order to have it perform line tracing and hole drilling of a complete circuit schematic layout onto a PCB card.

\section{REFERENCES}

[1] Hodges SE, Richards RJ. Looking for a better robot: visual robot control for cheap, flexible assembly. In Proceedings of the IEEE 5th International Conference on Image Processing and its Applications ; July 1995 ; Edinburgh, UK ; pp. 707-711. 
[2] Hodges SE. Looking for a cheaper robot: Visual feedback for automated PCB manufacture. PhD thesis. Cambridge University Engineering Department, Cambridge, U.K., 1996.

[3] Hodges SE, Richards RJ. Un-calibrated stereo vision for PCB manufacture. In IEE Colloquium on The Application of Machine Vision. May 1995 ; pages 1-6.

[4] Onwubolu GC, Aborhey S, Singh R, Reddy H, Prasad M, Kumar S, Singh S. Development of a PC-based computer numerical control drilling machine. Proceedings of Institution of Mechanical Engineers, Part B: Journal of Engineering Manufacture ; 2002 ; Vol: 216, No:11 ; pages:1-7.
[5] Salihmuhsin M, Baba S, Yılmaz AS, Şekkeli M. Design and Implementation of an Automated PCB Drawing and Drilling System. International Journal of Engineering Research and Development Journal (IJERAD), 2012. Volume 4, Issue 2, pages 43-45.

[6] Salihmuhsin M, Baba S, Yılmaz AS, Şekkeli M, Dizibüyük A, İzbudak H. An Improved Driving Circuit with TIP41C and TIP42C Transistors to Speed Up Operation of PCB Machine. International Journal of Przeglad Elektrotechniczny (Electrical Review) Journal, 2013. Volume 2013, Issue 01a/2013, pages 248-251. 